\title{
In defence of traditional cost and management accounting
}

\author{
R. K. Srivastava \\ Professor, Dept. of Finance, Asia Pacific Institute of Management, New Delhi, India
}

Corresponding Author:

Email: rajeev118@hotmail.com

\begin{abstract}
The theory and practise of traditional cost and management accounting has been under severe criticism in recent years. Professionals working in industry and academia world over have critically debated over traditional concept's relevance for cost control, performance appraisal, product costing/pricing and decision-making purposes. Critics contend that in a world class manufacturing environment (WCM) characterised by concepts of just in time (JIT) and total quality management (TQM), traditional costing becomes redundant as a performance measurement, decision making and cost control tool (Johnson,1987). They argue that traditional costing induces dysfunctional behaviour amongst employees because of fear of adverse variances being attributed to them (Birnberg. 1992) and also promotes the concept of cost plus pricing (Kaplan, 1984) which is not relevant in the modern day dynamics where selling prices are decided by market forces. Concepts as target costing and activity based costing are thought of to be more appropriate in today's manufacturing environment.

The impact of these criticisms has had a profound impact on the way this subject is perceived, be it academia or the industry or professional bodies regulating the profession of accounting. Arguments in favour of traditional costing still remain, however, the winds of changes appear continuous .A long and time tested language is being pushed into oblivion, being replaced with tools and techniques of the modern era which have and are being brought forward as betterments over the so called limitations of the traditional structure

The objective of this paper is two fold;

1. To identify various limitations attributed to traditional cost and management accounting in modern competitive environment.

2. To critically examine these various limitations in terms of both assumptions and objectives attributed by critics to the functional domain of cost and management accountancy.
\end{abstract}

\section{Introduction}

One of the immediate fallout of globalisation is increase in cross border flow of goods and services thereby increasing competition amongst business houses to an unprecedented level. Critics argue that Traditional Cost and Management Accounting is based on the assumption that profitability depends on capacity utilisation of physical assets like plant and machinery; control of raw materials like iron and steel; and overheads like repair and maintenance, power and fuel etc, in other words, on efficient utilisation of available infrastructure. It is also felt that traditional cost and management accounting is more suited to a static business environment with lengthy product life cycles and monopolistic environment, a characteristic found in the era of the Industrial Revolution. In those times 'arms length transactions' between cost and profit centres was a common practise with manufacturing carrying highest incidence of expenses when compared with other components of Value Chain. Also, product life cycles were long because of which little was needed to be spent on the 'other than manufacturing parts' of the Value Chain e.g., Research, Development, Marketing, Distribution or Customer Support. In such a scenario, the collection and assimilation of historical cost information was suffice, however, it is argued that such information fell woefully short when needed to be used strategically for decision making purposes in a globally competitive scenario.

\section{Limitations attributed to traditional cost and management accounting}

The limitations that have been attributed to the traditional concepts of cost accounting are as follows:

1. Projection of fixed overheads and estimated selling price in a Cost Sheet is a circular exercise with no added value.(Ferrara,1995)

In an award winning article," Cost / Management Accounting: THE $21^{\mathrm{ST}}$ CENTURY PARADIGM", published in Management Accounting (USA), December 1995, William L Ferrara argues that while preparing a Cost Sheet, one of the objectives of which is to assist management in pricing products, a professional cannot project fixed overheads until and unless he is aware of the production quantum to be effected. The forecast of future production can only be made if a tentative selling price of the product is known because, in a competitive market, it is the selling price which decides the sale quantity and therefore the production volume. The authors contend that in case the selling price is known at the time of projecting fixed overheads then the re computation of the same is a valueless exercise.

2. Traditional costing concentrates on manufacturing costs; however costs related to other portions of the value chain like research and development, marketing and customer support are equally important. (Johnson et al,1987) 
This criticism is a result of the frequent use of the cost accounting function for determining cost of goods produced in order to facilitate the preparation of financial accounts. Johnson and Kaplan's (1987) landmark text "RELEVANCE LOST : THE RISE AND FALL OF MANAGEMENT ACCOUNTING" attributes the period between 1900 to 1985 as the time when emphasis had shifted from Cost Management to Cost Accounting because of the increasing powers of financial auditors.

3. Traditional costing tools like standard costing induce a static behaviour in the employees.

During the past decade and a half, various writers (Johnson et al 1987, Moden et al 1993) have questioned the productivity and use of traditional systems such as standard costing and variance analysis. They argue that the use of standard costing renders employees static and curbs innovation and that companies following traditional standard costing find it difficult to improve upon standards because of severe resistance from employees who are convinced that the established best practise cannot be improved further.

4. Fear of adverse variances forces managers to give undue importance to material price, labour rate and efficiency and capacity utilisation. These concepts are detrimental to the modern day world class manufacturing environment characterised by concepts of JIT and TQM.(Shillinglaw,1989)

In a World Class Manufacturing environment, characterised by Just in Time policies, the focus of the management is to produce only as much as is required. This requires purchase of small quantities of raw material, increase in the number of set ups and minimal importance to capacity utilisation. Policies like this result in increased adverse variances related to raw material prices, labour efficiency and production volume. Critics argue that the fear of such adverse variances affects goal congruence and forces managers to behave against their company's policies.

5. Principles of absorption costing induce production managers to build stocks in order to increase the profitability of their department.(Shillinglaw,1989)

It is contended that production managers will be inclined to lock the fixed overheads in the closing inventory in order to show better profitability. This shall be done by producing to the optimum possible level giving little regard to the saleability of the produce. Such a situation is detrimental for a company which is operating in a world class environment characterised by JIT policies.

6. Traditional costing places undue emphasis on allocation basis like labour hours or machine hours.
This could result in wrong projection of Product costs. (Shillinglaw1989 , Johnson/Kaplan, 1987)

The use of labour hours or machine hours as a cost driver is criticised on the following two grounds;

i. Rapid industrialisation has made the use of direct labour redundant. Today, labour costs are more in the nature of fixed overheads( it may be noted that empirical studies conducted by various researchers like Garrett, Hunt and Merz (1995) and others have revealed that many front line companies like HP, IBM etc have abandoned direct labour reporting).

ii. In case where a plant is partly automated, the use of either labour hour or machine hour as an allocation base shall result in computation of wrong Product costs.

7. Traditional costing does not recognise the variability component in costs related to both complexity and diversity(Johnson, 1988)

Johnson and Kaplan argue that decisions related to product strategy usually pertain to periods between 3 to 5 years and in this time scale many of the costs considered to be traditionally 'fixed' are actually variable in nature. Such costs in traditional costing are either locked in the direct labour component or considered as a part of fixed overheads. Hence, when product costs are computed using traditional costing, these costs are allocated using allocation bases like labour hours available or imputed as fixed cost per unit. This leads to an erroneous estimated product cost per unit. It is argued that since these costs can fluctuate widely in an uncertain production environment, they should be treated separately as is done in Activity based costing.

8. Traditional costing reports functional costs whereas business is run through processes which are cross functional in nature.(Church,1931)

The emphasis placed by traditional cost and management accounting on costs depicting the organisational structure e.g. production costs, administration overheads etc is debatable. Such a system restricts organisations in understanding costs or resources consumed by processes/activities which are inevitably cross functional in nature e.g. the placement of a purchase order is a cross functional activity involving personnel's from various departments like Stores, Production, Accounts, Purchase, Quality Control etc...

9. Traditional costing provides historical information which may not be of much use for management decision making(Vatter,1950)

In a Total Quality Management environment, feedback required is real time so as to take corrective action. Traditional tools like Standard costing etc are unable to provide real time results and so are not suitable to be used. 
The problem of historical information is also referred to in the context of the valuation of raw material issues. In this regard the choice between the original cost or the replacement value is a point of contention.

10. Costs of a product are locked in the designing stage and hence there is no use directing efforts to the production stage.(Johnson, 1988)

Critics contend that costs of a product are known to organisations at the time when the product is being designed, not when it is in production. In spite of this fact, traditional cost and management accountants continue emphasising upon the manufacturing portion of the value chain.

11. Traditional costing does not provide the management with what is the allowable cost; rather it emphasises on the standard or actual costs.(Hiromoto, 1991)

This is looked upon as one of the major reasons for lack of innovation especially in the global era where competition amongst companies is unprecedented. It is argued that techniques like Target costing are much more motivating when compared to Traditional costing since the former encourage the use of concepts like value engineering and value analysis.

12. Traditional costing accepts a linear view of cost behaviour(Staubus,1987)

In an article written in The Accounting Historians Journal, 1987 titled 'The dark ages of cost accounting' George Staubus has questioned the linear assumption of cost adopted in most of the cost accounting text books. He argues that there is no justification in considering costs to behave linearly which in practice behave in a curvilinear fashion albeit with different shapes.

\section{Limitations - a critical appraisal}

A critical appraisal of limitations attributed to traditional cost and management accounting reveals the following:

1. Critics tend to confuse between cost information provided for different objectives. Critics have attributed specific but differencing objectives to cost and management accounting e.g. limitation No 1 criticises a traditional cost sheet of being a contentious document since projection of fixed overheads shall necessarily mean that the preparer of this document has a tentative selling price in his mind. This criticism assumes the following:

i. In a highly elastic pricing environment, there is no cost benefit in identifying the difference between the exact selling price based upon projections of experts and a tentative selling price.

ii. That companies operating in a high elastic pricing environment shall be using cost plus approach for pricing decisions. iii. That the prime objective of a Cost Sheet is to provide cost information to the management for pricing purposes.

iv. That the management is unaware of the uses of concepts of marginal cost / incremental costs for decision making purposes.

The first two assumptions are selfcontradictory as the relationship between the tentative selling price and the volume of activity shall only exist in a highly competitive environment where there is high elasticity between demand and price. In case such a scenario exists then it is extremely important to know the difference between what was tentatively thought and what the price would actually be as this would help in planning the short term volume of activity and inventory levels. Also, under such a business environment, it is most improbable that any company shall apply the cost plus approach towards pricing.

The third assumption takes a very narrow view point of the scope of a Cost Sheet as a utility document. It should be remembered that, in a competitive environment, the primary use of a Cost Sheet is not to fix prices but that of providing cost information to the management for control of projected costs, both fixed and variable.

The fourth assumption is self defeating as it assumes management to be ignorant of well known and established concepts of traditional cost and management accounting which advocate the use of relevant costs using incremental concepts rather than total absorbed costs in competitive scenarios.

Similarly limitation No 2 assumes the scope of cost and management accounting to be restricted to inventory valuation. The criticism is based upon various surveys done by researchers who concluded that inventory valuation is one of the primary objectives of cost accounting in the manufacturing industry. This may be true in companies where the majority of costs incurred are in the manufacturing division and products of which have long life cycles. Such companies frequently use information related to inventory valuations for decision making purposes. How can this be termed as a limitation of cost and management accounting? To attribute a limitation to a subject because of it being not utilised to its potential is wrong. In fact this limitation stems out of a very narrow approach of financial accounting which does not consider any expense beyond manufacturing as concerning production.

2. Behavioural problems of employees are being attributed to cost and management accounting.

Lack of motivation does not emerge from the use of traditional cost and management accounting as the critics would like us to believe. Refer to limitation no 3. It is argued that the use of 
traditional tools like standard costing renders employees static. Critics argue that the use of same standards year after year encourages employees to believe that perfection has been attained and there is no scope for improvement. However, this is a behavioural problem requiring motivational classes for employees to encourage innovation. It needs to be understood that the establishment of a standard related to material or labour or the utilisation of overheads is primarily an engineering function, the output of which is used by the accountants to arrive at standard money values. Hence, if a time and motion study has not given an optimum result or some other concern has arrived at a better way of doing similar work or the employees of a particular organisation are unwilling to innovate, the blame needs to be fixed, but certainly not upon cost and management accounting.

Limitation no 4 takes the blame game to absurd levels. It is contended that in a TQM environment characterised by JIT practises, the use of traditional tools like standard costing promotes incongruent behaviour in employees because of fear of adverse variances. Hence they would buy more rather than buying in small quantities, produce more rather than producing in small quantities and stock more rather than carrying minimal inventory. The argument pre supposes that the standard setters are unaware of company's policies and have hence established standards against the company's interest. It further assumes that performance is measured on the basis of such detrimental standards, thereby implying that along with the standard setters, the performance evaluators (usually from the top management) are also unaware of the company's policies. Both these assumptions are hard to digest. Limitation no 5 may be understood in similar context.

3. Advocates of Activity Based Costing misinterpret the principle of cost benefit in traditional costing.

Limitation No 6, 7 and 8 are mostly attributed to the traditional concepts by advocates of Activity Based Costing. The use of allocation basis like labour or machine hours is thought to provide with wrong and misleading information on product costs. However, it is no secret that by increasing the number of allocation basis, any company can 'close in' to the precise product cost. The more the allocation basis, the more precise is the projected cost. In case companies use fewer 'allocation basis' they do it for cost benefit and not because of any hard bound rule prohibiting them from getting better and more precise results.

Critics argue that traditional costing does not address the costs related to diversity and complexity. However, this criticism is based upon various surveyed established practises rather than on the potential of traditional concepts being capable of delivering e.g. in case of a TQM environment, the standard setters can well establish the standard labour hours available for production after taking into account the 'set up' time. Similarly incremental cost analysis could help management understand the cost implication of a new product to be added to the existing product structure.

Advocates of $\mathrm{ABC}$ further highlight the importance of processes rather than the organisational structure. They contend that it is the cross functional process which runs a business whereas traditional cost and management accounting collects and projects costs on functional basis. The argument is well taken, however, the fact remains that there is nothing in cost accounting literature that suggests that activities cannot or should not be considered as cost centres.

4. Computerised packages have made the limitation of historical information redundant.

Limitation number 9 addresses the problem of the usefulness of historical information. However, in the modern day context, when the use of integrated accounting has been adopted by all computerised packages, the limitation no longer exists. Integrated accounts provide up to date information on the state of Work In Progress, Raw Material and Finished Goods at all point of times, the accuracy of which is dependant on the design of allocations which may be done as per the needs of the concerned company. As regards the valuation of raw material issues, it needs to be understood that the established traditional practises are well equipped to imbibe variations in issue valuation policies, the decision of which needs to be taken by practitioners and the management.

5. Cost control / reduction at the designing stage is not a cost and management accounting function

There are no two doubts that costs which are likely to be incurred for production are known at the designing stage. Value engineering and value analysis are two popular techniques used to reduce costs at the pre production stage. However, these techniques are as much an engineering function as motivation is to HRD and writing of accounts is to an accountant. Limitation no $\mathbf{1 0}$ unfairly attempts to rest such responsibility on the cost and management accountancy function. Also, it needs to be understood that when traditional tools are used to control costs, they are concerned with the control of variations of predicated costs e.g. standard costs. With billions of dollars locked in such manufacturing costs, it is naïve to suggest that variations in such huge amounts are not important and should not be critically analysed or looked into. Imitation number 11 may be understood in a similar context. 
6. Traditional cost and management accounting does not consider cost to behave in a linear fashion

Limitation no $\mathbf{1 2}$ is perhaps the most widely used and least debated criticism. It is true that text book methods like those of the scatter graph or interpolation are of little use and based upon a linear view of cost behaviour, however, it is also true that these methods are good approximations and very useful when a large portion of volume related activity is heavily automated a characteristic of the modern day industry. In cases where such techniques render themselves insufficient, traditional cost and management accounting provides the curvilinear view of marginal cost which with the modern computer technology can cope with complicated, non-linear cost behaviour.

\section{Conclusion}

Although there has been a lot of criticism of traditional cost and management accounting, it may be wrong to attribute deficiencies to the subject and its underlying concepts. 'Single cost for multiple purposes' being replaced with 'multiple costs for multiple purposes' is welcome; however it needs to be remembered that the problem was with the selection of the cost object and the limited efforts put to trace variability, rather than the subject itself.

\section{References}

1. Cooper R (1990) Explicating the logic of ABC, Management Accounting, November.58-60.

2. Drury, C, Braunds Osborne, P. and Tayles, M(1992) A survey of management accounting practices in UK manufacturing companies, ACCA research occasional paper, Chartered Association of Certified Accountants.

3. Kaplan R.S. and Atkinson, AA (1989) Advanced Management Accounting, Prentice Hall.

4. William L Ferrara. 1995 "Cost/ Management Accounting: The 21st Century Paradigm”, Management Accounting (USA).

5. Johnson, H. Thomas; Kaplan, Robert S., Jan 1987 The Rise and Fall of Management Accounting Management Accounting; Harvard Business School Press

6. Monden, Y. and J. Y. Lee. 1993. How a Japanese auto maker reduces costs. Management

Accounting (August):22-6.

7. Shilling law, G. 1989. Managerial cost accounting: Present and future. Journal of Management Accounting Research (1):33-46.(wrong product costing, cost control behaviour)

8. Berliner, C., and J. A. Brimson, eds. 1988. Cost Management for Today's Advanced Manufacturing: The CAMI Conceptual Design. Harvard Business School Press.

9. Cooper, R. 2000. Cost management: From Frederick Taylor to the present. Journal of Cost Management (September/October):4-9.

10. Johnson, H. T. 1987. The decline of cost management: A reinterpretation of 20th-century cost accounting. Journal of Cost Management (Spring):5-12.
11. Johnson, H. T. 1992. Relevance Regained: From TopDown Control to Bottom-up Empowerment. The Free Press.

12. Johnson, H. T. and A. Broms. 2000. Profit beyond Measure: Extraordinary Results through Attention to Work and People. The Free Press.

13. Kaplan, R. S. 1983. Measuring manufacturing performance: A new challenge for managerial accounting research. The Accounting Review (October): 686-705.

14. Kaplan, R. S. 1984. The evolution of management accounting. The Accounting Review (July): 390-418.

15. Noreen, E. 1987. Commentary on H. Thomas Johnson and Robert S. Kaplan's Relevance Lost. Accounting Horizons (December): 110-6.

16. Vatter, William Joseph., 1950. Managerial accounting. Prentice-Hall Church, A. H. 1931. Overhead: The cost of production preparedness. Factory and Industrial Management:38-41.

17. Johnson, H. T. 1988. Activity based information: A blueprint for world class management accounting. Management Accounting (June):23-30.

18. George Staubus 1987: 'The dark ages of cost accounting' The Accounting Historians Journal.

19. Hiromoto, T. 1991. Restoring the relevance of management accounting. Journal of Management Accounting Research (3):1-15.

20. R. Hunt, L. Garrett, C.M. MerzDirect Labor Cost Not Always Relevant at H-P. Management Accounting (February 1985), pp. 58-62. 